\title{
EFFECT UTILIZATION MANGROVE Rhizophora sp FRUIT EXTRACT IN PRODUCTION OF COFFEE POWDER IN PERSPECTIVE OF WATER CONTENT AND ORGANOLEPTIC TEST
}

\author{
Raka Nur Sukma ${ }^{1}$. Mahfudlotus Zahro ${ }^{1}$
}

Ringkasan Utilization of mangrove seeds is not as popular the use of wood tree. Utilization of wood from mangrove tree is used as raw material for making charcoal and building materials.The local community rarely uses mangrove seeds for food, drinks, scrubs and coloring. This is not enough of public knowledge about the benefits of mangrove seeds. The public mindset that the only sources of carbohydrates are rice and corn. There is not much knowledge about the potential and benefits of mangrove seeds as a coffee drink. The research method used in this research is experimental research. In this experiment, 3 repetitions of treatment and 3 replications. Water content data in the mangrove seed ground coffee was tested by normality test. The proximate test results show ash content of 1 to $4 \%$ when averaged is $2.6 \%$. While the general requirement for roasted coffee (SNI.01.2983-1992) is 7-14\% ash content. The color of coffee is influenced by the value of the extract content of the coffee, water soluble coffee juice

\footnotetext{
1) Program Studi Ilmu Kelautan, Fakultas Perikanan dan Ilmu Kelautan Universitas Ronggolawe Jl. Manunggal N0 61 Wire Gedong ombo, Tuban Jawa Timur E-mail: raka.sukma2385@gmail.com
}

will give it a deep black color (Pastiniasih, 2012). The juice content of magrove coffee is high enough for each treatment so that the steeping gives a visually visible black color.

Keywords mangrove, extract, coffee, water content, organoleptic

\section{PENDAHULUAN}

Mangrove adalah tanaman dikotil yang bisa beradaptasi dan hidup di perairan yang mengandung salinitas tinggi. Ciri - ciri mangrove sangat khas sekali dengan struktur perakarannya (Tunjang). Jenis Rhizophora sp. di dunia dikenal secara umum sebagai red mangrove. Pohon ini dapat tumbuh hingga mencapai ketinggian $30 \mathrm{~m}$ dengan diameter batang kurang lebih $50 \mathrm{~cm}$ (Anwar, 2006). Secara ekologis area mangrove sering digunakan sebagai tempat untuk pemijahan, habitat bermain atau tempat mencari makan (Kordi and Ghufran, 2012). Sebagai tempat pemijahan, area mangrove berperan penting karena menyediakan tempat naungan serta mengurangi tekanan predator. Mangrove jenis Rhizopora sp sering dimanfaatkan se- 
cara langsung sebagai bahan bakar, kayu untuk rumah, bahan sintetik, bahan baku kertas dan lain-lain. Mangrove Rhizophora sp hampir tidak pernah dimanfaatkan sebagai bahan baku kosmetik dan minuman.

Pemanfaatan mangrove jenis Rhizophora sp menjadi kopi mempunyai potensi besar didalam inovasi produk minuman. Biji mangrove yang banyak tidak termanfaatkan dapat menjadi minuman kopi yang bisa dikonsumsi. Pemanfaatan biji mangrove sebagai bahan pembuatan minuman kopi bubuk sudah dilakukan oleh masyarakat sekitar hutan mangrove, namun hanya dilakukan di wilayah tertentu dan oleh sebagian kecil masyarakat. Hal itu dikarenakan kurangnya pengetahuan masyarakat tentang pengolahan biji mangrove jenis Rhizophora sp. Minuman kopi dari biji mangrove Rhizophora sp masih perlu pengkajian lebih lanjut tentang keamanan pangan, kandungan dan gizi. Diharapkan penelitian ini dapat memberikan dampak positif bagi ekonomi masyarakat sekitar hutan mangrove.

Tujuan dari penelitian ini adalah untuk mengetahui pemanfaatan serbuk biji mangrove jenis Rhizopora sp dalam pembuatan kopi bubuk dengan komposisi yang berbeda berpengaruh terhadap kadar air dan uji organoleptiknya.

\section{MATERI DAN METODE}

Pengambilan sample penelitian yaitu jenis serbuk biji mangrove dan serbuk biji kopi . Kemudian sample di timbang kurang lebih $10 \mathrm{~g}$. proses penyangraian biji kopi yang tergantung pada waktu dan suhu ditandai dengan perubahan kimiawi yang signifikan, Kopi yang telah disangrai kemudian digiling untuk mendapatkan kopi bubuk. Penggilingan dilakukan dengan alat pengiling (grinder).

Analisis data menggunakan penelitian eksperimen. Pada percobaan ini dilakukan ulangan sebanyak 3 kali perlakuan dan 3 kali ulangan, Data kadar air didalam kopi bubuk buah mangrove diuji dengan uji normalitas. Uji normalitas adalah uji yang dilakukan untuk mengetahui apakah sebuah data berdistribusi normal (Ghozali, 2006). Analisis ragam (ANOVA) dilakukan untuk mengetahui kadar air dalam kopi bubuk mangrove. Analisa statistik untuk pengolahan data pada penelitian ini yaitu dengan menggunakan uji $\mathrm{F}$ rancangan percobaan. Selanjutnya untuk mengetahui apakah ada perbedaan nyata diantara perlakuan yang diberikan, maka dilakukan perbandingan.

\section{HASIL DAN PEMBAHASAN}

\section{Kadar air}

Kadar airsuatu bahan perlu diketahui, karena air dapat mempengaruhi cita rasa mempengaruhi daya tahan bahan selama penyimpanan. Kandungan air dalam bahan menentukan daya tahan bahan terhadap serangan mikroorganisme ( Winarno, 2019).

Kadar air yang diharapkan dari kopi mangrove dengan dilakukan penjemuran dan penyangraian adalah mendapatkan kadar air terendah, hal tersebut ditunjukkan pada tabel 3.1 yaitu kadar air kopi mangrove setelah penjemuran yaitu rata- rata $6 \%$.

Rahardjo (2012) menyatakan standart mutu kadar air biji kopi adalah $<12,5 \%$. 
Tabel 1 Hasil analisis proksimat

\begin{tabular}{cccccc}
\hline No & $\begin{array}{c}\text { Berat Basah } \\
(\mathrm{g})\end{array}$ & $\begin{array}{c}\text { Berat Kering } \\
(\mathrm{g})\end{array}$ & $\begin{array}{c}\text { kadar abu } \\
(\%)\end{array}$ & $\begin{array}{c}\text { kadar air } \\
(\%)\end{array}$ & $\begin{array}{c}\text { kadar air sangrai } \\
(\%)\end{array}$ \\
\hline 1 & 5 & 3,1 & 1,2 & 6,05 & 2,01 \\
2 & 5 & 3,3 & 1,15 & 6,07 & 1,97 \\
3 & 5 & 3,1 & 1,13 & 6,01 & 1,8 \\
4 & 10 & 6,2 & 3,01 & 61,5 & 1,13 \\
5 & 10 & 5,9 & 2,09 & 6,15 & 1,76 \\
6 & 10 & 6,3 & 3,05 & 6,09 & 1,93 \\
7 & 15 & 9,3 & 4,2 & 6,17 & 1,51 \\
8 & 15 & 9 & 4,01 & 6,04 & 1,74 \\
9 & 15 & 9 & 3,95 & 6,06 & 1,81 \\
\hline
\end{tabular}

Kadar air pada kopi mangrove setelah disangrai selama 5-10 menit menunjukkan penurunan kadar air, Tabel 1. menunjukkan rata-rata kadar air kopi mangrove setelah disangrai adalah $1,7 \%$. Syarat umum kopi sangrai (SNI.01-29131992) yaitu kadar air maksimal adalah $4 \%$.

\section{Kadar Abu}

Kadar abu menunjukkan jumlah material yang terdapat dalam suatu bahankandungan pada kopi dapat berupa unsur yang dibutuhkan tanaman adalah pertumbuhan. Menurut Mertin et al (2014) kandungan materian dalam kopi dipengaruhi oleh kandungan hara dilingkungan tempat tumbuhnya dan penggunaan pupuk selama pemeliharaan.

Hasil uji proksimat yang ditunjukkan pada tabel 4.1 yaitu kadar abu 1 hingga $4 \%$ jika dirata-rata adalah $2,6 \%$. sedangkan syarat umum kopi sangrai (SNI.01.2983-1992) yaitu kadar abu 7$14 \%$. Dari hasil yang ditunjukkan pada tabel 4.1 tentang kadar abu rata-rata $2,6 \%$, berarti kadar abu didalam kopi magrove sesuai dengan syarat umum kopi sangrai ( SNI.01.2983-1992).

\section{Organoleptik kopi}

Uji organoleptik merupakan salah satu indikator untuk mengetahui tingkat penerimaan konsumen terhadap suatu produk, evaluasi sensorik dilakukan terhadap beberapa produk pangan, seperti penampakan, aroma, konsistensi, tekstur, dan rasa. Selanjutnya, evaluasi sensori dapat digunakan untuk berbagai tujuan, seperti pemeliharaan mutu produk, optimasi produk, pengembangan produk baru, dan pendugaan pasar yang potensial. Terdapat beberapa pengujian organoleptik, jenis pengujian yang dipilih tergantung tujuan apa yang diinginkan.

Pada penelitian ini, uji organoleptik yang digunakan adalah uji hedonik (kesukaan) terhadap kopi mangrove. Pada uji organoleptik, panelis yang menguji merupakan konsumen yang suka minum kopi.

Terdapat 6 faktor yang mempengaruhi karakteristik sensori kopi, yaitu varietas tanaman, lokasi/kondisi tumnbuh, metode pengolahan, tingkat penyangraian,kehalusan bubuk dan cara penyajian. Pengujian penelitian ini menggunakan 3 faktor dari uji organoleptik yaitu warna,aroma,tekstur.

\section{Warna}

Kopi murni memiliki warna lebih pekat jika dibandingkan dengan kopi instan

Gambar diatas adalah kopi mangrove yang sudah dikeringkan dan telah dilakukan penyangraian. Dari uji kuesioner sebagai besar panelis menilai suka terhadap warna dari kopi mangrove karena memiliki warna hitam pekat seperti kopi murni.

Warna kopi dipengaruhi oleh nilai kadar sari dari kopi, sari kopi yang larut dalam air akan memberikan warna hitam pekat. Kadar sari kopi magrove cukup tinggi untuk setiap perlakuan 

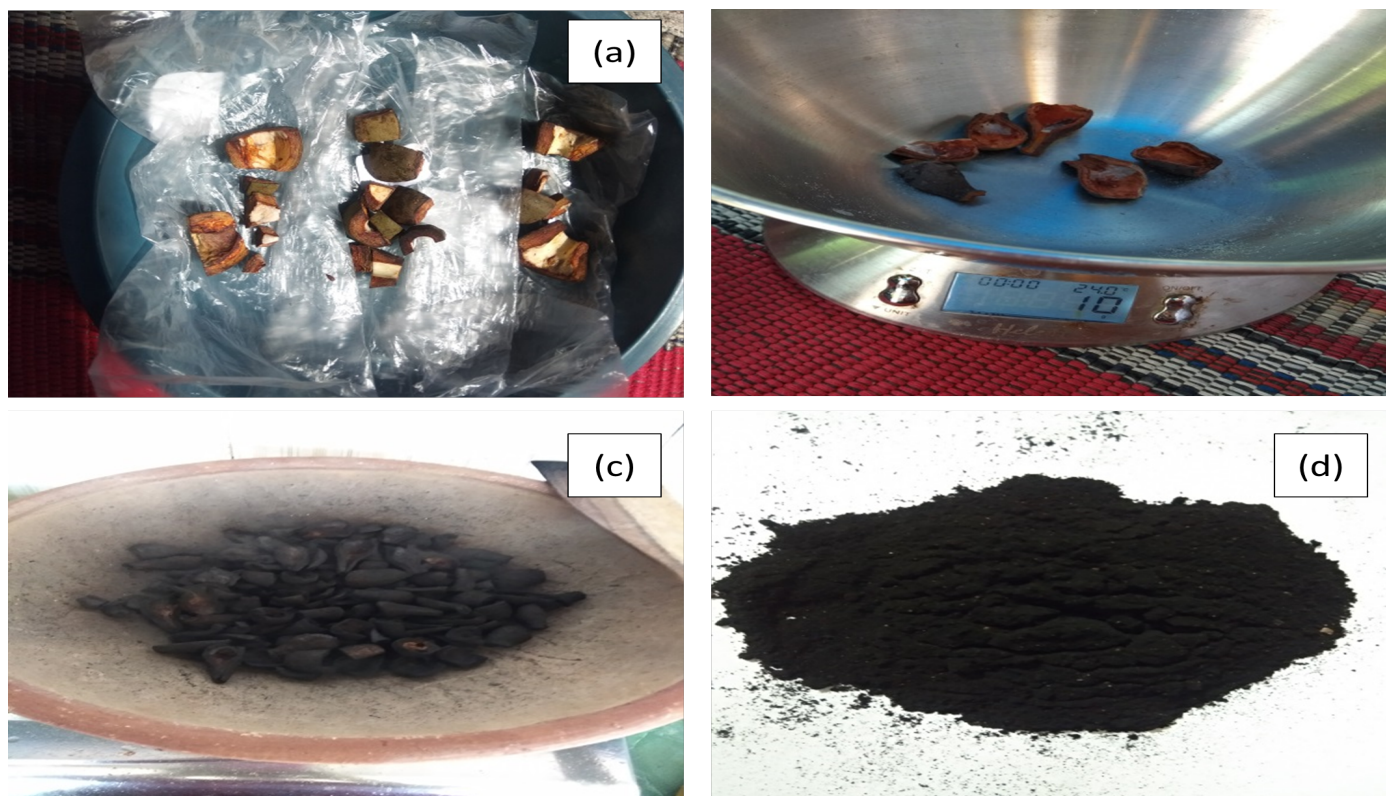

Gambar 1 Pembuatan kopi mangrove; penjemuran (a), hasil penjemuran 3 hari (b), setelah di sangrai (c), kopi bubuk (d)

sehingga hasil seduhannya memberikan warna hitam yang tampak secara visual.

Dari jumlah total 15 panelis seluruhnya menyukai warna kopi mangrove, karena warna bubuk kopi mangrove berwarna hitam pekat hal tersebut menjadi daya tarik bagi panelis. Warna kopi mangrove yang dihasilkan sangat dipengaruhi pada lamanya penyangraian.

\section{Aroma}

Aroma bubuk kopi timbul karena adanya senyawa senyawa yang mudah menguap. Senyawa yang mudah menguap dari kopi terbentuk selama proses penyangraian. Dalam pembuatan kopi senyawa akan dengan mudah menguap ketika dilarutkan dalam air panas agar ikut terekstrak dan membentuk aroma. Sebagaian besar senyawa mudah menguap yang tidak tahan terhadap panas akan mengalami kerusakan selama proses ekstraksi dan pengeringan. Hasil pengujian panelis sebanyak 15 panelis diperoleh bahwa panelis menyukai aro- ma kopi magrove, dengan alasan aroma yang ditimbulkan kopi magrove khas kopi. Dalam pembuatan kopi mangrove senyawa-senyawa mudah menguap, hal tersebut dilarutkan dalam air panas agar terekstrak dan membentuk aroma kopi mangrove yang sangat khas.

\section{Tekstur}

Tekstuk kopi mangrove terbentuk karena proses pengeringan dibawah sinar matahari. Tekstur bubuk kopi mangrove disukai oleh penelis, karena mempunyai tekstuk yang halus.

Dari 15 panelis yang menyukai tekstur kopi mangrove sebanyak 13 penelis. Proses penghalusan kopi mangrove tidak begitu sulit jika dibandingkan dengan penghalusan kopi mangrove dengan menggunakan blender, bubuk yang dihasilkan mempunyai tekstur halussama dengan tekstur bubuk kopi murni. 


\section{SIMPULAN}

Kadar air kopi mangrove setelah disangrai menit menunjukkan penurunan kadar air dengan sebagian besar panelis menilai suka dengan warna dari kopi magrove, karena memiliki warna hitam pekat seperti kopi, tekstur kopi bubuk mangrove halus, dengan proses yang tidak begitu sulit jika dibandingkan dengan penghalusan kopi murni.

\section{Pustaka}

Anwar, C. (2006). Manajemen dan teknologi budidaya karet. In Prosiding Seminar Tekno Ekonomi Agribisnis Karet.

Ghozali, I. (2006). Aplikasi analisis multivariate dengan program SPSS. Badan Penerbit Universitas Diponegoro.

Kordi, K. and Ghufran, M. (2012). Ekosistem mangrove potensi, fungsi, dan pengelolaan. Rineka Cipta. Jakarta.

Rahardjo, P. (2012). Panduan Budidaya dan Pengolahan Kopi Arabika dan Robusta.

Winarno, F. G. (2019). Kimia pangan dan gizi. Rineka Cipta.

Kontribusi: Sukma, R.N :Megambil data lapangan dan manuscript; Zahro, M:Analisis data dan Menulis Pembahasan 
